\title{
Family history of venous thromboembolism and mortality after venous thromboembolism: a Swedish population-based cohort study
}

\author{
Bengt Zöller ${ }^{1}\left[\right.$ Mirnabi Pirouzifard $^{1} \cdot$ Jan Sundquist $^{1} \cdot$ Kristina Sundquist $^{1}$
}

Published online: 19 December 2016

(C) The Author(s) 2016. This article is published with open access at Springerlink.com

\begin{abstract}
Studies on whether family history $(\mathrm{FH})$ of venous thromboembolism (VTE) affects long-term mortality after VTE are missing. The aim of this study was to determine whether FH of VTE affects long-term mortality after a first episode of VTE. Using Swedish medical databases, we conducted a 30-year nationwide cohort study of 49,159 adult Swedish born patients included in the multigeneration register (born 1932 or later) with a first-time VTE (1981-2010). Using Cox regression, we assessed mortality Hazard ratios (HRs) with 95\% confidence intervals (CIs). Totally 10,093 (20.5\%) patients with VTE had a first-degree FH of VTE (parent/sibling). Patients without FH of VTE had significantly more VTE provoking risk factors and comorbidities than those with FH. The mortality HR the first 10-years after first time VTE was decreased for those with FH of VTE compared to for those without FH: crude HR $0.807,95 \%$ CI $0.771-0.845$ and adjusted HR $0.864,95 \%$ CI $0.826-0.905$. After 10-years of followup there was no significant effect of FH of VTE on mortality: crude $\mathrm{HR}=1.018,95 \%$ CI $0.905-1.145$ and adjusted $\mathrm{HR}=0.995$, 95\% CI 0.884-1.119. Cancer-associated mortality was more common in those without FH the first 10 years $(56.9$ vs. $53.4 \%, \mathrm{p}=0.002)$. After 10 years there were no difference in cancer-associated mortality ( 4.9 vs. $5.6 \%$, $\mathrm{p}=0.604)$. The results suggest that patients with $\mathrm{FH}$ of
\end{abstract}

Electronic supplementary material The online version of this article (doi:10.1007/s11239-016-1464-y) contains supplementary material, which is available to authorized users.

Bengt Zöller

bengt.zoller@med.lu.se

1 Center for Primary Health Care Research, Skåne University Hospital, Lund University/Region Skåne, CRC, Building 28, Floor 11, Entrance 72, 20502 Malmö, Sweden
VTE have lower thrombotic threshold and need less provoking factors and comorbidities. They have also slightly lower total and cancer mortality the first 10 years after VTE.

Keywords Venous thromboembolism - Deep venous thrombosis $\cdot$ Pulmonary embolism $\cdot$ Mortality $\cdot$ Family history $\cdot$ Genetics $\cdot$ Comorbidity

\section{Introduction}

Venous thromboembolism (VTE), including deep venous thrombosis (DVT) and pulmonary embolism (PE), is a frequent occurring cardiovascular disease [1]. It is a multicausal disease caused by a number of interacting acquired and inherited risk factors [1]. A number of studies have reported the long-term mortality after VTE [2-14]. However, no study has reported whether family history of VTE affects the mortality and prognosis of a first time VTE. Several studies have shown that family history of VTE is a risk factor for first time VTE with a two- three-fold increased risk for primary VTE when a first-degree relative is affected, reviewed by Zöller et al. [15]. Though family history of VTE is linked to major or classical thrombophilias it is an independent risk factor for VTE [15-17]. Family history of VTE is a less important risk factor for recurrent VTE [18-22]. Two studies have found no such association while three studies have found a slight to moderate effect only [18-22].

We undertook this nationwide population-based cohort study to examine 30-year VTE mortality according to family history of VTE when controlling for VTE subtypes, underlying provoking factors and comorbidities. 


\section{Methods}

We used data from several Swedish registries linked by the unique individual Swedish personal identity number assigned to all residents of Sweden (at birth or immigration) [23-27]. A random number replaced the personal identity number in order to preserve confidentiality. Linking the following sources created the database used in the present study: the Total Population Register; the Multi-Generation Register; the Swedish Hospital Discharge Register; and the Swedish Register of Causes of Death. The Swedish hospital discharge records contains diagnosis at discharge classified according to the International Classification of Diseases (ICD), 8th revision (1969-1986), 9th revision (1987-1996) and 10th revision (1997-2010). The Swedish Total Population Register provided information about sex, country of birth, mortality and birth year.

\section{Inclusion of patients}

Patients were born 1932 or later. Only cases with a first time VTE were included at age of 18 years or older. VTE was defined as a main or secondary diagnosis of Deep Venous Thrombosis (DVT), Pulmonary Embolism (PE), or a combination of DVT and PE (PD) in the hospital discharge register occurring 1981-2010. Deep Venous Thrombosis (DVT) was defined as the following (ICD8: 451), (ICD-9: 451) and (ICD-10: I80). Pulmonary Embolism (PE) was defined as the following (ICD-8: 450), (ICD-9: 415B) and (ICD-10: I26). Combination of DVT and PE (PD) was defined as the following (ICD-8: 450, 451), (ICD-9: 415B, 451) and (ICD-10: I26, I80). Patients with only superficial thrombosis (ICD-10 code I800 or ICD-9 code 451A) were excluded. Patients with a VTE between 1968 and 1981 were excluded. Only Swedish born individuals were included. No information about ethnicity exist in the Swedish registers, only country of birth. Adopted patients were also excluded. A total 245,156 individuals with first time VTE diagnosis at age 18 years or older between 1981 and 2010 were identified from the Hospital Discharge Register. Of those individuals we identified 49,159 patients (offspring) who meet the inclusion criteria as named above. The date for first time VTE we call the index date.

\section{Ascertainment of cases}

The validity of the Swedish Hospital Discharge register is high and especially for cardiovascular disorders including VTE the validity is around $90-95 \%$ [25, 27, 28].

\section{Main predictor}

The Swedish Multigeneration Register, which contains information on family relationships, was used to assess the main predictor. The register contains information on index persons registered in Sweden after 1 January 1961 and born on or after 1 January 1932 [24]. Family history of VTE was defined as a main or secondary diagnosis of VTE (DVT or PE) in the hospital discharge register occurring any time between 1968 and 2010 in adult firstdegree relatives (siblings and/or parents) at age of 18 years or older by ICD codes for VTE described above. Main and secondary diagnosis in the hospital discharge register were included.

\section{Co-variates included in the analysis}

Included co-variates were age, sex, education, type of first time VTE manifestation (DVT, PE, or PD, see above), and comorbidities. Comorbidities were defined by main or secondary diagnosis in the Swedish Hospital discharge register according to ICD-8, ICD-9 or ICD-10 codes occurring between 1968 and first event of VTE (i.e. at index date). The ICD codes for the included comorbidities are listed in Supplement Table 1. The studied comorbidities were cancer, hypertension, atrial fibrillation/flutter, obesity, psychiatric disease, coronary heart disease (CHD), heart failure, psychiatric disease, peripheral vascular disease, cerebrovascular disease, liver disease, varicose veins, inflammatory bowel disease (IBD), asthma, and other pulmonary diseases (chronic obstructive pulmonary disease, emphysema, bronchiectasis,

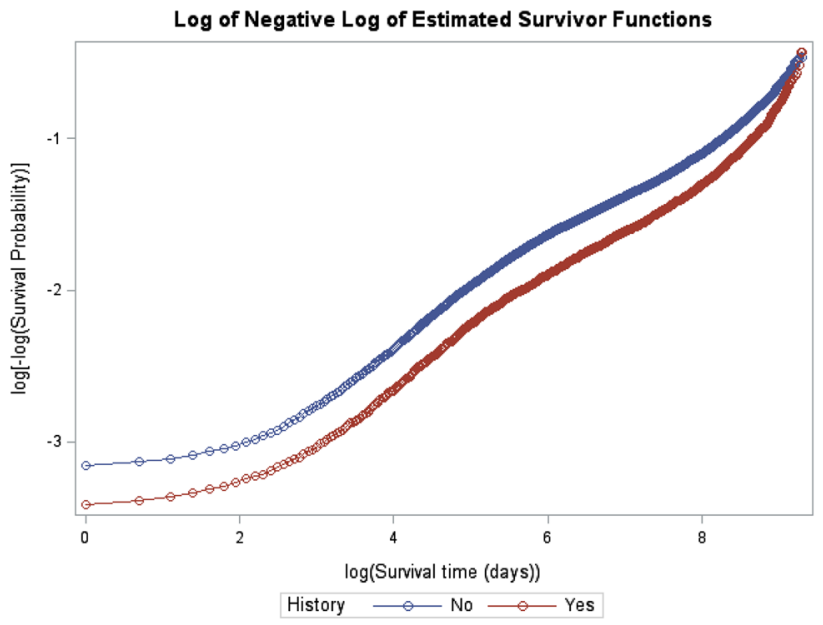

Fig. 1 Logarithm (Log) of negative logarithm of estimated survivor functions. This Log-Log plot indicates that the curves diverge after 3650 days ( 10 years) 
interstitial pulmonary disease, and pneumoconiosis). Pregnancy/delivery, fractures/trauma, and surgery needed to occur within 90 days before first time VTE (the index date).

\section{Statistical analysis}

We used Cox proportional-hazards models to calculate hazard ratios (HRs) and 95\% confidence intervals [29]. The Cox model time scale was follow-up time from the first diagnosis registration between 1981 and 2010, until emigration, death, or the end of follow-up (December 31,2010 ), whichever occurred first. In all models, we investigated the proportional hazards assumption by including an interaction term between diagnosis and the time. However, there was a significant interaction between time and family history of VTE ( $<0.001)$. The log of negative log of survival plot without adjusting for other covariates in Fig. 1 show that the survival curves seems to diverge after 3650 days (10 years). The graphical approach indicates that the assumption of proportionality over time is violated. Thus, time affects the relative mortality risk and we can conclude that the risks in our model are not proportional. We therefor considered time-dependent variables for diagnosis and used an extended cox model (Heaviside functions). Multivariate models were adjusted for age, sex,
Table 1 Characteristics of patients $(\mathrm{N}=49159)$ with first time venous thromboembolism (VTE), i.e. deep venous thrombosis (DVT), pulmonary embolism (PE), or combined DVT and PE (PD)

\begin{tabular}{|c|c|c|c|}
\hline & No $\%(39,066)$ & Yes \% $(10,093)$ & $\mathrm{P}$ \\
\hline \multicolumn{4}{|l|}{ History $(49,159)$} \\
\hline \multicolumn{4}{|l|}{ Diagnosis } \\
\hline DVT & 46.6 & 46.6 & \multirow[t]{3}{*}{$<0.001$} \\
\hline PD & 5.1 & 6.2 & \\
\hline PE & 48.4 & 47.3 & \\
\hline \multicolumn{4}{|l|}{ Sex } \\
\hline Female & 49.0 & 46.4 & \multirow[t]{2}{*}{$<0.001$} \\
\hline Male & 51.0 & 53.6 & \\
\hline \multicolumn{4}{|l|}{ Age } \\
\hline Median (IQR) & $55(44-63)$ & $55(46-63)$ & \\
\hline \multicolumn{4}{|l|}{ Education } \\
\hline Low (0-9 years) & 32.0 & 34.2 & \multirow[t]{4}{*}{$<0.001$} \\
\hline Middle (10-11 years) & 44.6 & 44.1 & \\
\hline Higher (12 years or more) & 22.9 & 21.2 & \\
\hline Unknown & 0.6 & 0.5 & \\
\hline Asthma $^{\mathrm{a}}$ & 3.5 & 3.0 & 0.018 \\
\hline Atrial fibrillation $^{\mathrm{a}}$ & 4.9 & 4.4 & 0.030 \\
\hline Cancer $^{\mathrm{c}}$ & 20.8 & 17.3 & $<0.001$ \\
\hline Cerebrovascular disease $\mathrm{a}^{\mathrm{a}}$ & 6.2 & 6.5 & 0.333 \\
\hline Congestive heart failure $^{a}$ & 4.1 & 3.5 & 0.005 \\
\hline Coronary Heart disease $^{a}$ & 7.6 & 6.8 & 0.005 \\
\hline Diabetes $^{\mathrm{a}}$ & 7.2 & 6.5 & 0.012 \\
\hline Fractures/Trauma ${ }^{\mathrm{b}}$ & 6.7 & 5.9 & 0.005 \\
\hline Hypertension $^{\mathrm{a}}$ & 14.4 & 14.4 & 0.917 \\
\hline Inflammatory bowel disease ${ }^{a}$ & 2.3 & 2.0 & 0.068 \\
\hline Liver disease $^{\mathrm{a}}$ & 1.2 & 0.9 & 0.014 \\
\hline Obesity $^{\mathrm{a}}$ & 2.1 & 2.0 & 0.670 \\
\hline Peripheral vascular disease $^{\mathrm{a}}$ & 3.6 & 3.8 & 0.351 \\
\hline Pregnancy/delivery ${ }^{\mathrm{b}}$ & 1.4 & 1.1 & 0.059 \\
\hline Psychiatric disease $^{\mathrm{a}}$ & 14.0 & 13.2 & 0.036 \\
\hline Pulmonary disease except asthma $^{\mathrm{a}}$ & 4.0 & 3.9 & 0.576 \\
\hline Varicose veins $^{\mathrm{a}}$ & 2.8 & 3.2 & 0.033 \\
\hline Surgery ${ }^{\mathrm{b}}$ & 16.9 & 15 & $<0.001$ \\
\hline
\end{tabular}

${ }^{a}$ Any time before or at index date

${ }^{\mathrm{b}}$ Within 90 days before and at index date

${ }^{\mathrm{c}} 5$ years before or at index date 
education, type of first VTE (DVT; PE; PD), comorbidities and provoking VTE risk factors. SAS, version 9.3 (SAS Institute, Inc., Cary, North Carolina) was used for analyses.

\section{Ethical approval}

The study was approved by the Ethics Committee of Lund University, Sweden (approval number 409/2008, with amendments approved on September 12009 and January 22 2010). It was performed in compliance with the Declaration of Helsinki. Consent was not obtained but the presented data were anonymized thus eliminating any risk of identification.

\section{Results}

\section{Patient characteristics}

Between years 1981 and 2010, a total of 49159 VTE patients (offspring), born in Sweden and aged 18 years or older, were identified on the basis of their first discharge recorded in the Hospital Discharge Register (Table 1). Among the identified VTE patients, 39066 (79.5\%) patients included had no family history of VTE (NH) and 10093 (20.5\%) VTE patients had a family history (YH) of VTE. There were slightly more females $(49.0 \%)$ in $\mathrm{NH}$ group than in the $\mathrm{YH}$ group (46.4\%). Median age among $\mathrm{NH}$ patients was 55 years with Interquartile Range (IQR) (44-63 years) and 55 years (IQR 46-63 years) among YH patients. A higher proportion of patients with family history of VTE had PD than patients without family history (6.2 vs. 5.1\%). A similar proportion of patients had manifestations of pulmonary embolism (PE + PD: 53.5 vs 53.5\%) but a higher proportion had DVT among patients with family history of VTE (DVT+PD: 52.8 vs. 51.7\%). There were also a slightly higher proportion of individuals with low education among those with family history of VTE.

\section{Comorbidities and provoking risk factors}

Several comorbidities or provoking risk factors were slightly but significantly more common among patients with no family history of VTE than among those with family history: asthma (3.5 vs. $3.0 \%$ ), atrial fibrillation/flutter (4.8 vs. 4.3 ), cancer (20.8 vs. 17.3), congestive heart failure (4.1 vs. 3.5$)$ coronary heart disease (7.6 vs. $6.8 \%$ ), diabetes mellitus ( 7.2 vs. $6.5 \%$ ), fracture/trauma (6.7 vs. $5.9 \%$ ), pregnancy/delivery (1.4 vs. $1.1 \%)$, psychiatric disease (14.0 vs. 13.2 ), liver disease (1.2 vs $0.9 \%$ ), and surgery (16.9 vs. $15 \%$ ). The opposite relationship was observed for varicose veins. Patients in YH group had slightly but significantly
Table 2 Mortality rate and survival probability for patients with index date from 1981 to 2010 by family history

\begin{tabular}{lllll}
\hline & \multicolumn{2}{l}{ No $(39,066)$} & \multicolumn{2}{l}{ Yes $(10,093)$} \\
\cline { 2 - 3 } \cline { 5 - 6 } & $(\%)$ & $\begin{array}{l}\text { Survival prob- } \\
\text { ability }\end{array}$ & $(\%)$ & $\begin{array}{l}\text { Survival } \\
\text { probabil- } \\
\text { ity }\end{array}$ \\
\hline 1 week & 4.9 & 0.952 & 3.9 & 0.962 \\
1 month & 7.1 & 0.929 & 5.5 & 0.945 \\
3 months & 10.8 & 0.892 & 8.4 & 0.916 \\
1 year & 16.9 & 0.828 & 13.3 & 0.864 \\
5 years & 23.2 & 0.751 & 19.2 & 0.794 \\
10 years & 26.3 & 0.698 & 22.2 & 0.745 \\
15 years & 28.0 & 0.654 & 24.1 & 0.699 \\
20 years & 28.8 & 0.614 & 25.2 & 0.652 \\
25 years & 29.2 & 0.572 & 25.7 & 0.593 \\
29 years & 29.3 & 0.531 & 25.8 & 0.521 \\
\hline
\end{tabular}

more varicose varices $(3.2 \%$ vs. $2.8 \%)$ than patients in $\mathrm{NH}$ group.

\section{Mortality after a first event of VTE}

From index date till the end of follow-up on 31 December 2010 (Table 2), a total of 39066 patients with NH, 29.3\% died, as compared with $25.8 \%$ patients in the $\mathrm{YH}$ group (Table 2). The 10 years mortality rate in patients with $\mathrm{NH}$ was $26.3 \%$ compared to $22.2 \%$ in YH individuals (Table 2). The survival probability is also shown in Table 2. Median follow-up time was 1963 days for NH patients (IQR 405-4 661 days) and 2459 days among YH patients (IQR 598-5 082 days) $(p<0.001)$. In Fig. 2 the Kaplan-Meier plot by family history of VTE is presented. Family history was associated with a better survival $(\mathrm{p}<001)$. Table 2 indicates that the mortality rate after 10 years was lower than before 10 years. Based on survival curves in Fig. 1 we divided time to event in two time periods, time $>3650$ days and time $\leq 3650$ days (Table 3 ). The crude estimated mortality HR for $\mathrm{YH}$ in time $\leq 3650$ is 0.807 (95\% CI 0.771-0.845) indicating YH have an estimated 19.3\% lower mortality than NH. Estimated mortality HR for time $>3650$ goes up to 1.018 (95\% CI 0.905-1.145). In the adjusted models adjustment was made for all variables presented in Table 1. Estimated mortality HR in adjusted model is 0.846 (95\% CI $0.826-0.905$ ) for time $\leq 3650$ days and it is 0.995 (95\% CI 0.884-1.119) for time $>3650$ days.

\section{Mortality in different subtypes of VTE}

Instead of adjusting for the presentation of VTE (i.e. DVT, PE, PD) we also analyzed patients with DVT, PE, and PD separately (Supplement Tables 2-4). Similar pattern were 


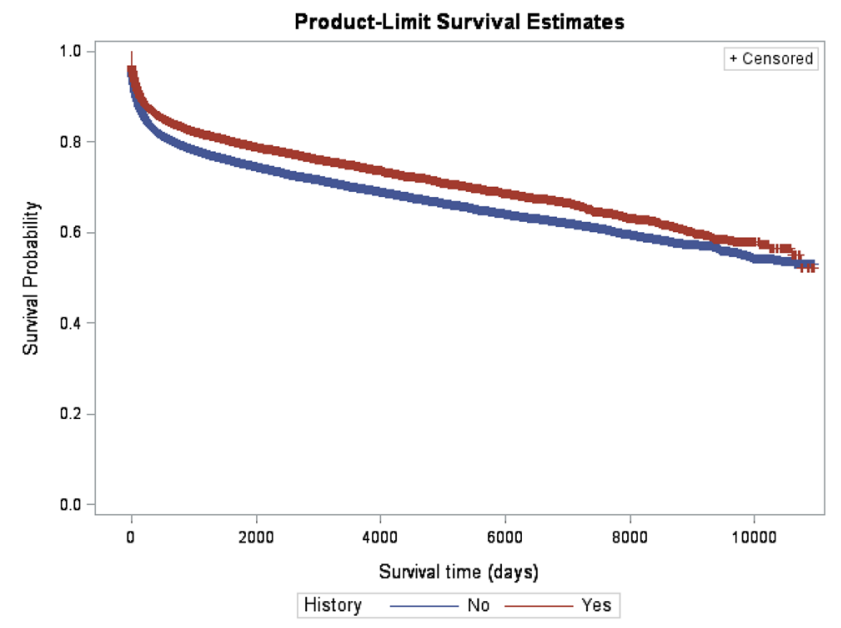

Fig. 2 Kaplan-Meier plot by family history of venous thromboembolism (VTE). The survival was significantly higher among those with family history of VTE $(\mathrm{p}<0.001)$

observed both in the crude model and full models with significantly decreased mortality the first 10 -years of follow up for those with family history and no significant difference in mortality during follow up between 10 and 30 years. In the PD group the decreased mortality among those with family history of VTE during the first 10 years was significant only in the crude model probably due to the lower number of patients in this group (crude model $0.799,95 \% \mathrm{CI}$ $0.653-0.978$ and full model $0.841,95 \%$ CI $0.685-1.032$ ). Among DVT and PE patients the decreased mortality for those with family history of VTE was significant in both the crude and adjusted models (DVT crude model 0.813, 95\% CI 0.759-0.869, and DVT full model $0.921,95 \%$ CI 0.86-0.986, PE crude model 0.807 , 95\% CI 0.756-0.861, and PE full model $0.826,95 \%$ CI $0.774-0.881$ ).

\section{Comorbidity related mortality}

In Supplement Table 5 are shown the overall HR for comorbidities in the multivariable model. Cancer was the strongest predictor for mortality ( $\mathrm{HR}=8.11,95 \% \mathrm{CI} 7.812-8.42$ ). Among the 10,226 NH patients who died the first 10 years after first event of VTE 56.9\% had cancer compared with $53.4 \%$ of the $2225 \mathrm{YH}$ patients who died $(\mathrm{p}=0.002)$. After more than years of follow up only $4.9 \%$ of the $1221 \mathrm{NH}$ patients who died had cancer compared with $5.6 \%$ of 376 YH patients $(\mathrm{p}=0.604)$. Other comorbidity associated mortality than cancer was not significantly higher the first 10 years after VTE for NH compared with YH patients.

Other significant predictors for mortality were: congestive heart failure $(\mathrm{HR}=1.695,95 \%$ CI $1.584-1.815)$, peripheral vascular disease $(\mathrm{HR}=1.249,95 \%$ CI 1.158-1.346), coronary heart disease $(\mathrm{HR}=1.171,95 \%$ CI 1.106-1.24), cerebrovascular disease $(\mathrm{HR}=1.495$, 95\% CI 1.411-1.584), diabetes mellitus $(\mathrm{HR}=1.491,95 \%$ CI 1.41-1.577), psychiatric disease ( $\mathrm{HR}=1.468,95 \% \mathrm{CI}$ 1.404-1.535), other pulmonary disease $(\mathrm{HR}=1.504,95 \%$ CI 1.403-1.611), and liver disease $(\mathrm{HR}=2.197,95 \% \mathrm{CI}$ 1.956-2.468).

Some conditions were associated with lower mortality: pregnancy/delivery $(\mathrm{HR}=0.222,95 \%$ CI $0.133-0.368)$, hypertension ( $\mathrm{HR}=0.924,95 \%$ CI $0.88-0.97)$, fracture/ trauma, $\quad(\mathrm{HR}=0.859,95 \%$ CI $0.791-0.933)$, varicose veins $(\mathrm{HR}=0.862,95 \% \mathrm{CI}$ 0.779-0.953), and asthma $(\mathrm{HR}=0.848,95 \%$ CI $0.773-0.931)$.

Surgery (HR $=1.007,95 \%$ CI $0.966-1.05)$ and obesity $(\mathrm{HR}=1.002,95 \% \mathrm{CI} 0.882-1.139)$ were not associated with mortality.

\section{Other factors associated with mortality}

Increasing age was associated with mortality $(\mathrm{HR}=1.033$ per year, 95\% CI 1.031-1.035). Female sex $(\mathrm{HR}=0.958$, 95\% CI $0.927-0.991)$ and high education (12 or more years compared with 9 years or less education: $\mathrm{HR}=0.76$, 95\% CI 0.725-0.797) had lower mortality. Patient with both DVT and PE had slightly higher mortality compared with DVT patients (HR $=1.101,95 \%$ CI 1.063-1.139). There was no significant difference between DVT and PE $(\mathrm{HR}=1.035,95 \%$ CI $0.953-1.124)$.

\section{Discussion}

To the best of our knowledge this is the first paper to confirm Roosendaal's theory in a large epidemiological study that familiarly predisposed individuals have a lower thrombotic threshold [1]. In this population-based 30-year

Table 3 Stratified mortality hazard ratios (HRs) before and after 10 years of follow up in patients with venous thromboembolism

\begin{tabular}{llllllll}
\hline & Reference & Follow up time & HR $^{\mathrm{a}}$ & 95\% CI & & HR $^{\mathrm{b}}$ & 95\% CI \\
\hline History & No & $\leq 3650$ & 0.807 & 0.771 & 0.845 & 0.864 & 0.826 \\
& & $>3650$ & 1.018 & 0.905 & 1.145 & 0.995 & 0.884 \\
\hline
\end{tabular}

Crude $^{\mathrm{a}}$ and adjusted ${ }^{\mathrm{b}}$ HRs are presented

${ }^{\mathrm{a}}$ Crude model, ${ }^{\mathrm{b}}$ Full model is adjusted for all variables in Table 1 
cohort study, we found that patients with a first-time hospitalization for VTE and family history of VTE compared with those without family history of VTE had a decreased risk of dying within the first 10-years after the event. VTE patients with family history of VTE also had less provoking factors and comorbidities than those without family history of VTE. The results are somewhat surprising as an increased risk for fatal PE have been reported among patients with family history of VTE [30]. However, in the published study the reference group was the general population without family history of VTE [30]. In the present study the reference group was patients with VTE without family history of VTE. As patients with VTE have significantly much higher mortality than the general population our results are not in opposition to the published study [14]. The result of our study is in line with the idea of a thrombotic threshold presented by Rosendaal [1]. Patients with a familial predisposition for VTE needs less circumstantial factor in order to provoke a thrombotic event. This explains why several comorbidities and provoking risk factors were more common among patients without family history of VTE. Adjustment for these factors decreased the mortality HR. However, residual confounding of comorbidities is likely to exist. The mechanism behind that family history of VTE after 10 years of follow-up is not protective anymore is unclear. However, it might be related to that several comorbidities such as cancer and different cardiovascular disorders have a severe prognosis and that many of these patients have died within 10 years. There was a dramatic difference in cancer associated mortality during the first 10 years of follow up compared with after more than 10 years of follow up.

An observation worth considering is that varicose veins were linked to family history of VTE confirming a previous study showing linkage between inheritance of varicose veins and increased risk of VTE suggesting shared familial susceptibility [31]. The observation of a slightly higher prevalence of DVT among patients with family history could be related to the factor $\mathrm{V}$ gene paradox, as factor $\mathrm{V}$ Leiden is highly prevalent in Sweden [32, 33].

A limitation of the present study is that we did not include outpatients, as there is no Swedish outpatient register before 2001. Less severe thrombotic events are therefore not included, which explains why the overall 30-year mortality was not significantly different among DVT and PE patients. However, outpatient treatment in Sweden did not start in a large scale until after the introduction of Low molecular weight heparin in Sweden 1994. However, with regards to the presence or absence of family history of VTE this is most likely a non-differential bias. Strength of the study design is the high coverage and high validity of the Swedish Hospital discharge register especially for cardiovascular disorders such as VTE [23, 25, 27, 28]. Another strength is using the multi-generation register together with the Swedish Hospital Discharge Register for defining family history, which eliminates recall bias. Our finding of decreased long-term mortality risk up to 10 years after VTE is likely generalizable to many Western societies but it may not apply to all ethnic groups. A limitation is the lack of information about ethnicity. It is important to note that only Swedish born VTE cases were included in the study. As only adults with VTE between 1981 and 2010 were included this means that a large majority of patients are of Scandinavian and/or European Caucasian origin.

The observation that family history of VTE is associated with less comorbidities and provoking factors and better initial prognosis is theoretically interesting confirming Roosendaal's theory of a thrombotic threshold [1]. However, the difference is too small to be able to use alone in the clinic but could be included in a risk assessment model.

\section{Conclusions}

We found that patients with family history of VTE have a better initial prognosis the first 10 years after first time VTE. Patients with family history of VTE have less provoking factors and less comorbidities indicating a lower thrombotic threshold.

Acknowledgements The registers used in the present study are maintained by Statistics Sweden and the National Board of Health and Welfare.

Funding This work was supported by grants awarded to Dr Bengt Zöller by the Swedish Heart-Lung Foundation, ALF funding from Region Skåne awarded to Dr Bengt Zöller and Dr Kristina Sundquist, grants awarded to Dr Bengt Zöller and Dr Kristina Sundquist by the Swedish Research Council, and grants awarded to Dr Jan Sundquist by King Gustaf V and Queen Victoria's Foundation of Freemasons. The funders had no role in study design; in the collection, analysis, and interpretation of data; in the writing of the report; and in the decision to submit the article for publication.

\section{Compliance with ethical standards}

Conflict of interest None.

Open Access This article is distributed under the terms of the Creative Commons Attribution 4.0 International License (http:// creativecommons.org/licenses/by/4.0/), which permits unrestricted use, distribution, and reproduction in any medium, provided you give appropriate credit to the original author(s) and the source, provide a link to the Creative Commons license, and indicate if changes were made. 


\section{References}

1. Rosendaal FR (1999) Venous thrombosis: a multicausal disease. The Lancet 353:1167-1173

2. Flinterman LE, van Hylckama Vlieg A, Cannegieter SC, Rosendaal FR (2012) Long-term survival in a large cohort of patients with venous thrombosis: incidence and predictors. PLoS Med 9:e1001155

3. Ng AC, Chung T, Yong AS, Wong HS, Chow V, Celermajer DS, Kritharides L (2011) Long-term cardiovascular and noncardiovascular mortality of 1023 patients with confirmed acute pulmonary embolism. Circ Cardiovasc Qual Outcomes 4:122-128

4. Reitter SE, Waldhoer T, Mayerhofer M, Eigenbauer E, Ay C, Kyrle PA et al (2011) Long-term survival of patients with a history of venous thromboembolism. Ann Hematol 90:585-594

5. Klok FA, Zondag W, van Kralingen KW, van Dijk AP, Tamsma JT, Heyning FH et al (2010) Patient outcomes after acute pulmonary embolism: a pooled survival analysis of different adverse events. Am J Respir Crit Care Med 181:501-506

6. Heit JA, Silverstein MD, Mohr DN, Petterson TM, O'Fallon WM, Melton LJ 3rd (1999) Predictors of survival after deep vein thrombosis and pulmonary embolism: a population-based, cohort study. Arch Intern Med 159:445-453

7. Prandoni P, Villalta S, Bagatella P, Rossi L, Marchiori A, Piccioli A et al (1997) The clinical course of deep-vein thrombosis.: prospective long-term follow-up of 528 symptomatic patients. Haematologica 82:423-428

8. Kniffin WD Jr, Baron JA, Barrett J, Birkmeyer JD, Erson FA Jr (1994) The epidemiology of diagnosed pulmonary embolism and deep venous thrombosis in the elderly. Arch Intern Med 154:861-866

9. Schulman S, Lindmarker P, Holmström M, Lärfars G, Carlsson A, Nicol P et al (2006) Post-thrombotic syndrome, recurrence, and death 10 years after the first episode of venous thromboembolism treated with warfarin for 6 weeks or 6 months. J Thromb Haemost 4:734-742

10. Tagalakis V, Patenaude V, Kahn SR, Suissa S (2013) Incidence of and mortality from venous thromboembolism in a real-world population: the Q-VTE Study Cohort. Am J Med 126:832.e13832.e21

11. Prandoni P, Lensing AW, Cogo A, Cuppini S, Villalta S, Carta M et al (1996) The long-term clinical course of acute deep venous thrombosis. Ann Intern Med 125:1-7

12. Spencer FA, Gore JM, Lessard D, Douketis JD, Emery C, Goldberg RJ (2008) Patient outcomes after deep vein thrombosis and pulmonary embolism: the Worcester venous thromboembolism study. Arch Intern Med 168:425-430

13. Naess IA, Christiansen SC, Romundstad P, Cannegieter SC, Rosendaal FR, Hammerstrøm J (2007) Incidence and mortality of venous thrombosis: a population-based study. J Thromb Haemost 5:692-699

14. Søgaard KK, Schmidt M, Pedersen L, Horváth-Puhó E, Sørensen HT (2014) 30-year mortality after venous thromboembolism: a population-based cohort study. Circulation 130:829-836

15. Zöller B, Li X, Ohlsson H, Ji J, Sundquist J, Sundquist K (2015) Family history of venous thromboembolism as a risk factor and genetic research tool. Thromb Haemost 114:890-900

16. Mannucci PM, Franchini M (2015) Classic thrombophilic gene variants. Thromb Haemost 114:885-889
17. Bezemer ID, van der Meer FJ, Eikenboom JC, Rosendaal FR, Doggen CJ (2009) The value of family history as a risk indicator for venous thrombosis. Arch Intern Med 169:610-615

18. Hron G, Eichinger S, Weltermann A, Minar E, Bialonczyk C, Hirschl M et al (2006) Family history for venous thromboembolism and the risk for recurrence. Am J Med 119:50-53

19. Gauthier K, Kovacs MJ, Wells PS, Le Gal G, Rodger M, REVERSE investigators (2013) Family history of venous thromboembolism (VTE) as a predictor for recurrent VTE in unprovoked VTE patients. J Thromb Haemost 11:200-203

20. Zöller B, Ohlsson H, Sundquist J, Sundquist K (2014) Family history of venous thromboembolism (VTE) and risk of recurrent hospitalization for VTE: a nationwide family study in Sweden. J Thromb Haemost 12:306-312

21. Sundquist K, Sundquist J, Svensson PJ, Zöller B, Memon AA (2015) Role of family history of venous thromboembolism and thrombophilia as predictors of recurrence: a prospective followup study. J Thromb Haemost 13:2180-2186

22. Bruzelius M, Ljungqvist M, Bottai M, Bergendal A, Strawbridge RJ, Holmström M et al (2016) F11 is associated with recurrent VTE in women. A prospective cohort study. Thromb Haemost 115:406-414

23. Rosen M, Hakulinen $\mathrm{T}$ (2005) Use of disease registers. In: Ahrens W, Pigeot I (eds) Handbook of epidemiology. SpringerVerlag, Berlin, pp 231-252

24. Ekbom A (2011) The Swedish multi-generation register. Methods Mol Biol 675:215-220

25. Ludvigsson JF, Andersson E, Ekbom A, Feychting M, Kim JL, Reuterwall C et al (2011) External review and validation of the Swedish national inpatient register. BMC Public Health 11:450

26. Ludvigsson JF, Otterblad-Olausson P, Pettersson BU, Ekbom A (2009) The Swedish personal identity number: possibilities and pitfalls in healthcare and medical research. Eur J Epidemiol 24:659-667

27. Zöller B (2013) Nationwide family studies of cardiovascular diseases-clinical and genetic implications of family history. EMJ Cardiol 1:102-113

28. Rosengren A, Fredén M, Hansson P-O, Wilhelmsen L, Wedel H, Eriksson H (2008) Psychosocial factors and venous thromboembolism: a long-term follow-up study of Swedish men. J Thromb Haemost 6:558-564

29. Breslow NE, Day NE (1987) Statistical methods in cancer research, volume II: the design and analysis of cohort studies. IARC Sci Publ 82:1-406

30. Zöller B, Li X, Sundquist J, Sundquist K (2012) A nationwide family study of pulmonary embolism: identification of high risk families with increased risk of hospitalized and fatal pulmonary embolism. Thromb Res 130:178-182

31. Zöller B, Ji J, Sundquist J, Sundquist K (2014) Venous thromboembolism and varicose veins share familial susceptibility: a nationwide family study in Sweden. J Am Heart Assoc 3:e000850

32. Bounameaux H (2000) Factor V Leiden paradox: risk of deepvein thrombosis but not of pulmonary embolism. Lancet 356:182-183

33. Zöller B, Norlund L, Leksell H, Nilsson JE, von Schenck H, Rosén U et al (1996) High prevalence of the FVR506Q mutation causing APC resistance in a region of southern Sweden with a high incidence of venous thrombosis. Thromb Res 83:475-477 